\title{
Betulin attenuated liver damage by prevention of hepatic mitochondrial dysfunction in rats with alcoholic steatohepatitis
}

\author{
V Buko ${ }^{1,2}$, I Kuzmitskaya ${ }^{1}$, S Kirko ${ }^{1}$, E Belonovskaya ${ }^{1}$, E Naruta $^{1}$, O Lukivskaya ${ }^{1}$, \\ A Shlyahtun ${ }^{1,2}$, T Ilyich ${ }^{3}$, A Zakreska ${ }^{2}$, I Zavodnik ${ }^{1,3}$ \\ ${ }^{1}$ Division of Biochemical Pharmacology, Institute of Biochemistry of Biologically Active Compounds, \\ National Academy of Sciences, Grodno, Belarus \\ ${ }^{2}$ Department of Biotechnology, University of Medical Sciences, Bialystok, Poland \\ ${ }^{3}$ Department of Biochemistry, Yanka Kupala State University of Grodno, Grodno, Belarus
}

Received: May 4, 2018

Accepted: July 15, 2019

\begin{abstract}
Betulin, a pentacyclic triterpene, possesses antioxidant, anti-inflammatory and hepatoprotective properties. The aim of this study was to evaluate the impact of liver mitochondria in hepatoprotection of betulin using a rat model of alcoholic steatohepatitis induced by ethanol administration $(4 \mathrm{~g} / \mathrm{kg}$, intragastric) for 8 weeks. The treatment with betulin ( 50 and $100 \mathrm{mg} / \mathrm{kg}$ b.w., intragastric) during this period attenuated the histological signs of steatohepatitis and lowered the serum and liver triglyceride contents, as well as the serum activities of aspartate aminotransferase, alanine aminotransferase, and alkaline phosphatase. Betulin $(100 \mathrm{mg} / \mathrm{kg})$ decreased the liver/body weight ratio and inhibited the increase in the serum levels of TNF $\alpha$, IL-1 $\beta$, TGF $\beta$, and hyaluronic acid, demonstrating hepatoprotective, anti-inflammatory, and antifibrotic potential. Betulin also inhibited the formation of superoxide anions in mitochondria and the end-products of lipid peroxidation in liver tissue, the amount of which was significantly increased in ethanol-treated rats. The disturbances in mitochondrial respiration, uncoupling of oxidative phosphorylation and decreasing of mitochondrial complex I, II, and IV activities in rats with steatohepatitis, were reverted by betulin administration. The increased susceptibility of mitochondria to $\mathrm{Ca}^{2+}$-induced permeability transition pore formation in the hepatitis group was improved in rats treated with betulin. In conclusion, betulin, having antioxidant properties, exerts a beneficial effect in the rat model of alcoholic steatohepatitis via prevention of liver mitochondria dysfunction, which may be attributed to the inhibition of mitochondrial permeability transition.
\end{abstract}

Keywords: liver, mitochondria, alcoholic steatohepatitis, betulin, mitochondrial permeability transition

\section{Introduction}

Excessive chronic consumption of ethanol provokes alcoholic liver disease, which represents one of the main causes of mortality in most parts of the world. Long-term alcohol consumption causes alcoholic steatosis, which can lead to alcoholic steatohepatitis (ASH), liver fibrosis or cirrhosis and, finally, to hepatocellular carcinoma. The transition of steatosis to ASH is stimulated by different exogenous and endogenous factors, which are able to induce oxidative stress, enhancing ethanol toxicity and stimulating production of proinflammatory cytokines, such as tumor necrosis factor alpha (TNF $\alpha)$ and interleukin-1 $\beta$

Corresponding author: Prof. Vyacheslav Buko, MD, $\mathrm{PhD}$

Division of Biochemical Pharmacology, Institute of Biochemistry of Biologically Active Compounds,

National Academy of Sciences

BLK-50, 230030 Grodno, Belarus

Phone: +375 152438 511; Fax: +375 152434 121; E-mail: buko@bioch.basnet.by 
(IL-1 $\beta$ ) (19). Activated by ethanol-induced oxidative stress, associated with reactive oxygen species (ROS) production by the mitochondrial respiratory chain, these cytokines trigger inflammation and apoptosis in the liver, which, in turn, promotes transition from steatosis to steatohepatitis. Disturbances in mitochondrial structure and functions are recognized as the earliest signs of liver damage by ethanol and contribute to the progress of alcoholic liver disease from steatosis to steatohepatitis (38). On the other hand, ethanol-stimulated ROS production promotes lipid peroxidation, with the end-products disturbing oxidative phosphorylation (5) and modifying mitochondrial DNA-encoding subunits of the electron-transport chain, which further amplifies ROS production. For therapeutic intervention to be successful, this vicious circle should be disrupted. Therefore, mitochondria are potential targets for prevention and treatment of ASH. The key role of oxidative stress in the pathogenesis of ASH suggests antioxidative treatment to be beneficial in the above pathology (28).

During the past decades, a lot of attention was drawn to the application of natural antioxidants (alone or in combination with pharmacological drugs) as potential therapeutic agents for the treatment of fatty liver diseases (14).

Betulin [lup-20(29)-ene-3, 28-diol] is a pentacyclic triterpene, which is widely distributed in many plants. In birch bark extracts, the contents of betulin can vary from $54 \%$ to $82 \%$ of dry weight (31). Betulin acts as a direct scavenger of free oxygen radicals (34). The antioxidant and anti-inflammatory properties of betulin (17) may be responsible for several pharmacological effects of this triterpen, including its hepatoprotective action (18).

The data on betulin effects in alcoholic liver damage are poorly presented in the current literature. Betulin ameliorated liver damage in mice with acute alcohol intoxication (36) where the beneficial effect of betulin on triglyceride accumulation in the liver is related to downregulation of SREBP-1c gene expression. In mice, fed with an ethanol-containing diet for 10 days, betulin decreased serum triglyceride content and improved liver histology (4). The authors proposed that the lipid-lowering effect of betulin could be realized not only through SREBP-1-mediated signaling, but also via the protein sirtuin 1, which exerts a marked effect on mitochondrial function (33). Mitochondria-associated mechanisms are also implicated in the antitumor effect of betulin (16) and in betulin protection against cadmiuminduced cell damage (26).

Based on these data, we proposed that betulin, protecting the liver in acute alcohol intoxication (36) and at the earlier stage of alcoholic steatosis (4), can be a promising hepatoprotector also at the advanced stages of alcoholic liver disease and ASH, and its beneficial effect can be connected with an improvement of liver mitochondrial function damaged by long-term alcohol intoxication. Therefore, this study was designed to evaluate the hepatoprotective effect of betulin, isolated, and purified in our laboratory from stem bark of birch (Betula pendula Roth.) (10), on experimental ASH through correction of ethanolinduced alterations in hepatic mitochondrial function.

\section{Materials and Methods}

\section{Chemicals}

Kits for serum marker enzyme activities were from LaChema (Brno, Czech Republic). Commercial ELISA kits for TNF $\alpha$, the transforming growth factor beta (TGF $\beta$ ), and IL-1 $\beta$ determination were obtained from R\&D Systems GmbH (Wiesbaden, Germany). The kit for measurement of hyaluronic acid was obtained from Wuhan USCN Sciences Co., Ltd. (Wuhan, China). Hypromellose (hydroxypropylmethylcellulose) was obtained from 
Shin-Etsu Chemical Co., Ltd. (Tokyo, Japan). All other chemicals were obtained from Sigma-Aldrich (St. Louis, MO, USA). Organic solvents were of analytical grade and used without further purification.

\section{Isolation and characterization of betulin}

The stem bark of birch (B. pendula Roth.) was collected from Pyshki forest of Grodno Regional Forestry, Belarus. The plant was authenticated by comparing with the herbarium specimen at the Institute of Experimental Botany, National Academy of Sciences, Minsk, Belarus (MSK).

The outer layer of the bark was dried in an oven at $100{ }^{\circ} \mathrm{C}$ to a constant weight, powdered, and then betulin was extracted with $95 \%$ ethanol using a continuous extraction technique. The crude extract was purified by double recrystallization from undecane. Betulin was isolated as a white fine crystalline solid, with melting point $257^{\circ} \mathrm{C}$. The purity of the isolated betulin was $98.9 \%$, as estimated by reverse phase HPLC using an Agilent 1200 HPLC system (Santa Clara, USA) equipped with a diode array detector. Chromatographic separation was achieved using a Zorbax RX C18 column $5 \mu \mathrm{m}$, $3.0 \times 150 \mathrm{~mm}(\mathrm{PN} 883967-302)$, using a mobile phase of $100 \%$ acetonitrile, and a detection wavelength of $210 \mathrm{~nm}$. The injection volume was $10 \mu \mathrm{l}$ of each sample diluted with acetonitrile to approximately $0.5 \mathrm{mg} / \mathrm{ml}$. The data obtained were processed using the Agilent ChemStation B03.04 software (Santa Clara, USA).

\section{Animal experiments and sampling}

The care, use, and procedures performed in this experiment were approved by the Ethic Committee of the National Academy of Sciences, Belarus (protocol no.: 29/16 of May 23, 2016) and complied with the European Convention for the Protection of Vertebrate Animals Used for Experimental and Other Scientific Purposes and the NIH guide for the Care and Use of Laboratory Animals (NIH publication no. 80-23; revised 1978).

Male albino Wistar rats with the initial body weight ranging from 200 to $230 \mathrm{~g}$ were used in this study. During 8 weeks, rats from all the groups were fed on a standard laboratory diet and had free access to tap water. The animals were divided into four groups (eight rats per group). Group 1 (control): rats received saline. Group 2 (EtOH): rats received ethanol (30\%, $\mathrm{vol} / \mathrm{vol})$ via gastric tube $(4 \mathrm{~g} / \mathrm{kg}$, between 9:00 and 10:00 a.m.) throughout the experiment (8 weeks). Group 3 (Bet 50): rats received betulin $(50 \mathrm{mg} / \mathrm{kg}$, between 4:00 and 5:00 p.m.) plus ethanol. Group 3 (Bet 100): rats received betulin $(100 \mathrm{mg} / \mathrm{kg}$, between $4: 00$ and 5:00 p.m.) plus ethanol. Betulin was suspended in $0.8 \%$ hypromellose before the intragastric administration.

The severity of alcoholic liver damage in animal modeling is dependent on the duration and dosage of the consumed ethanol. Since administration of the generally accepted liquid ethanol-containing Lieber-DeCarli diet for 4-12 weeks induces only mild liver injury with steatosis and low-grade liver inflammation (23), we applied intragastric administration of ethanol for 8 weeks to induce a more advanced stage of alcoholic liver disease. Earlier, we demonstrated that the chronic administration of ethanol $(4 \mathrm{~g} / \mathrm{kg})$ effectively provoked advanced alcoholic liver damage (21). The hepatoprotective dosage of betulin was chosen on the basis of the literature data (36).

The rats were decapitated under pentobarbital anesthesia after 12-h starving. Blood samples were collected and serum was obtained by centrifugation at 3,000 $\times g$. Liver samples for histopathological examination were taken from the left lobe. Part of the liver was 
immediately used for isolation of mitochondria. The remaining liver cubes were frozen in liquid nitrogen for further biochemical investigations.

\section{Liver histopathology}

Liver samples were randomly selected, fixed in Bouin's solution, and embedded in paraffin wax. Histological sections were prepared and stained with hematoxylin and eosin. Other liver samples were fixed in Becker solution for histochemical lipid determination. Cryostat sections were fixed and stained with Sudan Black. Tissue sections were imaged in an Olympus CX-41 light microscope (Olympus, Tokyo, Japan) using a 40× objective and the digital images were captured with an OlympusC-5060 camera (Olympus, Japan). The square of the Sudan Blackstained area was measured by computer-assisted morphometry using the ImageJ morphometric analysis software (NIH, USA). Liver slides stained with hematoxylin-eosin were examined to evaluate the hepatic inflammatory infiltration under a light microscope with high-power fields $(200 \times)$. We registered inflammatory foci consisting of three and more cells in 10 fields of view.

\section{Isolation of rat's liver mitochondria}

Mitochondria were isolated from rat's liver by differential centrifugation (13). We used an isolation medium containing $0.125 \mathrm{M}$ of $\mathrm{KCl}, 0.05 \mathrm{M}$ of sucrose, $0.01 \mathrm{M}$ of Tris- $\mathrm{HCl}$, $0.0025 \mathrm{M}$ of $\mathrm{KH}_{2} \mathrm{PO}_{4}, 0.005 \mathrm{M}$ of $\mathrm{MgSO}_{4}$, and 0.0005 $\mathrm{M}$ of EDTA, $\mathrm{pH}$ 7.4.

\section{Measurement of mitochondrial respiration rate}

Mitochondrial respiration was measured at $25{ }^{\circ} \mathrm{C}$ using a Clark oxygen electrode as we described earlier (22). The oxygen consumption rates in respiratory state $4\left(\mathrm{~V}_{4}\right)$ and ADP-stimulated $(0.3 \mathrm{mmol} / \mathrm{L})$ state $3\left(\mathrm{~V}_{3}\right)$ were monitored using as substrates pyruvate $(10 \mathrm{mmol} / \mathrm{L})+$ malate $(2.5 \mathrm{mmol} / \mathrm{L})$ to study NADH-linked respiratory pathway, or succinate $(10 \mathrm{mmol} / \mathrm{L})+$ rotenone $(5 \mu \mathrm{mol} / \mathrm{L})$ to study $\mathrm{FADH}_{2}$-dependent respiration. The respiratory control ratio (RCR) equal to the ratio of respiratory rates $\left(\mathrm{V}_{3} / \mathrm{V}_{4}\right)$ of mitochondria in state 3 and state 4 and the coefficient of phosphorylation (ADP/O ratio - the amount of ATP produced per total $\mathrm{O}$ consumed) were calculated.

\section{Measurement of respiratory chain complex activities}

Complex I and II activities were evaluated as NADH dehydrogenase and succinate dehydrogenase activities and measured as described by Singer (29). The activity of Complex IV (cytochrome c oxidase) was assessed by the absorbance of reduced cytochrome $c$ at $550 \mathrm{~nm}$ (37).

\section{Mitochondrial swelling determination}

$\mathrm{Ca}^{2+}$-induced swelling of isolated respiring mitochondria was measured, as we recently described (12). Briefly, the extent of the mitochondrial permeability transition (MPT) pore formation in mitochondrial suspension was determined from the absorbance at $520 \mathrm{~nm}$ and $25^{\circ} \mathrm{C}$ using a buffer containing $0.25 \mathrm{M}$ of sucrose, $0.02 \mathrm{M}$ of Tris- $\mathrm{HCl}$, and $0.001 \mathrm{M}$ of $\mathrm{KH}_{2} \mathrm{PO}_{4}, \mathrm{pH} 7.2$. Isolated mitochondria $(0.5 \mathrm{mg}$ of protein $/ \mathrm{ml})$ were added to the medium containing respiratory substrate $\left(5 \mathrm{mM}\right.$ of succinate). After $5 \mathrm{~min}, \mathrm{Ca}^{2+}$ ions $(40 \mu \mathrm{M})$ were added, and the rate $\left(\Delta \mathrm{D}^{520} / \mathrm{min}\right)$ of the termination phase of swelling was measured. At the end of the measurements, the uncoupler FCCP $(0.5 \mu \mathrm{M})$ was added to the mitochondria to control the completion of the MPT process. To evaluate the effect of cyclosporine A (CsA), an inhibitor of MPT pore formation on mitochondrial swelling, the mitochondria were pretreated with $2 \mu \mathrm{M}$ of $\mathrm{CsA}$ at $25^{\circ} \mathrm{C}$ for $3 \mathrm{~min}$. 


\section{Biochemical analysis}

The activities of the serum markers, alanine aminotransferase (ALT), aspartate aminotransferases (AST), and alkaline phosphatase were measured using standard commercial kits from Lachema (Brno, Czech Republic) according to the manufacturer's instructions and reported as IU/L. ROS generation in mitochondria was measured by NADPH-induced chemiluminescence enhanced by lucigenin, a chemiluminogenic probe for detecting superoxide anions $(16,24)$. Chemiluminescence intensity was expressed as counts per minute per milligram of protein.

The end-products of lipid peroxidation in liver tissue were measured as thiobarbituric acid-reacting substances (TBARS) (8) and expressed as nmol per $g$ of liver tissue. The hepatic reduced glutathione (GSH) level was assessed by the improved 5,5'-ditiobis(2-nitrobenzoic acid) method (1) and was expressed as $\mu$ mol per $g$ of tissue.

Liver and serum triglycerides were measured by routine methods using the commercial kit according to the manufacturer's instructions. The serum TNF $\alpha$, IL-1 $\beta$, TGF $\beta$, and hyaluronic acid were measured by ELISA techniques using the appropriate kits. Protein concentrations in liver tissue and mitochondria were determined by the method of Lowry et al. (20).

\section{Statistical analyses}

All the data are expressed as the mean \pm standard deviation $(M \pm S D)$. The data were analyzed statistically by the one-way analysis of variance (GraphPad Prism software v.5.0; San Diego, CA, USA) using the post-hoc analysis with Tukey's test. The level of significance was considered at $p<0.05$.

\section{Results}

\section{Hepatoprotective and anti-inflammatory effects of betulin}

Rats administered with ethanol had a significantly higher mean body weight and mean liver weight compared to the control group (Table I). The treatment with betulin did not affect body weight, but the higher dose $(100 \mathrm{mg} / \mathrm{kg})$ of betulin decreased the liver weight with statistical significance. Calculating liver/body weight ratio, we found that only this dose of betulin results in a decrease of this steatosis marker (35) as compared to the alcoholadministered rats.

The histological evaluation of control livers showed the expected normal architecture without pathological signs (Fig. 1A). The long-term administration of ethanol caused steatohepatitis, which was characterized by macro- and microvesicular steatosis, multifocal lymphocytic infiltration, and scattered parenchimal cells with ballooning degeneration (Fig. 1B). The morphometric evaluation of Sudan Black-stained liver preparations showed an increase in the relative square of the sudanophylic area on the alcohol-treated rat liver preparations (approximately 4.3-fold; Fig. 1F; Table I). The number of inflammation foci in this group exceeded 10 per field of view (Table I).

The treatment of alcohol-administered rats with betulin, especially with its high dose (100 mg/kg), essentially alleviated these pathological changes in the liver (Fig. 1C, D). The sizes of lipid vacuoles were much smaller compared to those in rats treated with ethanol alone. The morphometric evaluation of liver slices stained with Sudan Black B indicated a decrease of neutral lipid accumulation in the liver of rats treated with the higher dose of betulin $(100 \mathrm{mg} / \mathrm{kg})$. The number of inflammatory foci was significantly decreased under the influence of both the doses of betulin. 
Table I. Body and liver weights, relative liver weight, liver morphometric data, and triglyceride content in rats with alcoholic steatohepatitis treated with betulin

\begin{tabular}{|l|c|c|c|c|}
\hline & Control & ASH & $\begin{array}{c}\text { ASH + betulin, } \\
\mathbf{5 0} \mathbf{~ m g} / \mathbf{k g}\end{array}$ & $\begin{array}{c}\text { ASH + betulin, } \\
\mathbf{1 0 0} \mathbf{~ m g} / \mathbf{k g}\end{array}$ \\
\hline Body weight (g) & $329.4 \pm 16.3$ & $293.1 \pm 16.9^{\mathrm{a}}$ & $281.9 \pm 16.0^{\mathrm{a}}$ & $286.3 \pm 27.9^{\mathrm{a}}$ \\
\hline Liver weight (g) & $8.80 \pm 0.67$ & $9.94 \pm 0.86^{\mathrm{a}}$ & $9.15 \pm 0.66$ & $8.27 \pm 1.13^{\mathrm{b}}$ \\
\hline Liver/body weight ratio (\%) & $2.67 \pm 0.11$ & $3.42 \pm 0.24^{\mathrm{a}}$ & $3.1 \pm 0.19^{\mathrm{a}}$ & $2.88 \pm 0.14^{\mathrm{ab}}$ \\
\hline Sudanophylic area (\%) & $2.34 \pm 0.59$ & $9.67 \pm 2.01^{\mathrm{a}}$ & $8.63 \pm 1.64^{\mathrm{a}}$ & $8.08 \pm 2.30^{\mathrm{a}}$ \\
\hline Inflammatory foci (number) & n.d. & $10.3 \pm 0.76$ & $7.1 \pm 1.21^{\mathrm{b}}$ & $6.8 \pm 0.84^{\mathrm{b}}$ \\
\hline $\begin{array}{l}\text { Liver triglycerides, mg/g } \\
\text { wet tissue }\end{array}$ & $1.21 \pm 0.11$ & $3.45 \pm 0.69^{\mathrm{a}}$ & $2.85 \pm 0.65^{\mathrm{ab}}$ & $2.33 \pm 0.42^{\mathrm{ab}}$ \\
\hline
\end{tabular}

The data are presented as means \pm SD. Morphometric evaluation of the square of sudanophylic area (Sudan Black/ total area $\times 100$ ) for a mean of 12 pictures for each slide. The number of inflammatory foci per field of vision for a mean of eight pictures for each slide. n.d.: not detected.

Significant difference $(p<0.05)$ : ${ }^{\mathrm{a}} \mathrm{vs}$. that of the Control group; ${ }^{\mathrm{b}} \mathrm{vs}$. that of the ASH group

A

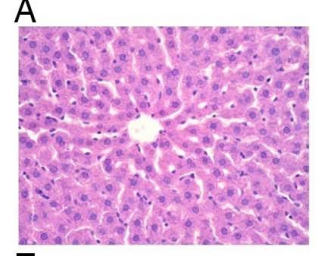

E

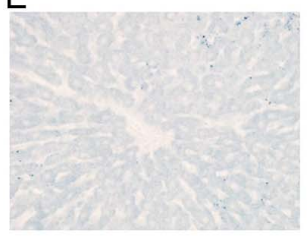

B

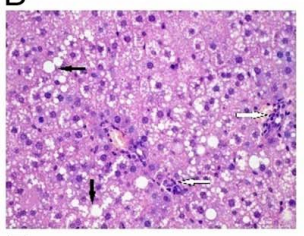

$\mathrm{F}$

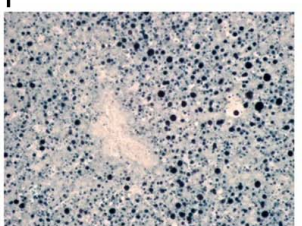

C

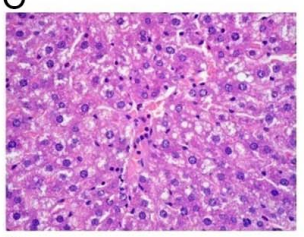

G

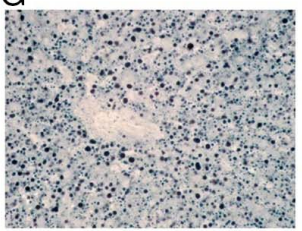

D

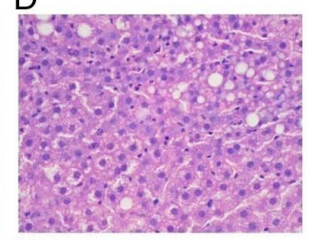

$\mathrm{H}$

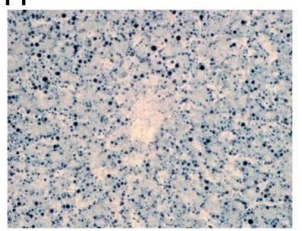

Fig. 1. Histological evaluation of the liver in betulin-treated rats with alcoholic steatohepatitis (ASH). Liver H\&E staining: A - Control; B - ASH; C - ASH + betulin, $50 \mathrm{mg} / \mathrm{kg}(\mathrm{ASH}+\mathrm{Bt} 50)$; D - ASH + betulin, $100 \mathrm{mg} / \mathrm{kg}$ $(\mathrm{ASH}+\mathrm{Bt100}) ; 400$. The black arrow represents macrovesicular infiltration; the white arrow - inflammatory foci. H\&E stained liver displaying normal liver architecture in the control group. The group administered with ethanol alone showed macro- and microvesicular steatosis, vacuolization and inflammatory foci. The signs of liver damage and degeneration were substantially reduced by betulin treatment, especially at the higher dose (ASH + Bt100). Liver Sudan Black B staining: E - Control; F - ASH; G - ASH + Bt50; H - ASH + ASH + Bt100; ×400. Stronger Sudan

Black B staining intensity was observed in the ASH group, which was then slightly reduced subsequent to betulin administration

The development of ASH in alcohol-treated rats was confirmed by biochemical data. The activities of the serum marker enzymes AST, ALT, and alkaline phosphatase were significantly elevated (Table II). Serum and liver triglyceride contents were markedly raised, which confirm enhanced accumulation of neutral lipids in the liver of the ethanol-treated group. The administration of ethanol substantially increased the serum levels of 
proinflammatory cytokines, TNF $\alpha$ and IL-1 $\beta$, and fibrogenic markers, cytokine TGF $\beta$, and hyaluronic acid.

The high dose of betulin $(100 \mathrm{mg} / \mathrm{kg})$ considerably decreased the activities of AST and ALT, whereas the activity of alkaline phosphatase remained unchanged as compared to the ethanol-treated group (Table II). The levels of both serum and liver triglycerides were lowered significantly and to the same extent after treatment with both betulin doses. Betulin $(100 \mathrm{mg} / \mathrm{kg})$ developed clear anti-inflammatory and antifibrotic effects, decreasing serum levels of TNF $\alpha$, TGF $\beta$, IL-1 $\beta$, and hyaluronic acid with statistical significance (Table II).

\section{Mitochondrial effects of betulin}

The administration of ethanol decreased parameters characterizing mitochondrial respiration (RCR) using substrates for complex I (pyruvate + malate) and complex II (succinate + rotenone; Fig. 2A, B). The high dose of betulin $(100 \mathrm{mg} / \mathrm{kg})$ significantly elevated RCR in rats treated with ethanol when both the oxidizing substrates were used, whereas the lower dose $(50 \mathrm{mg} / \mathrm{kg})$ increased this parameter without statistical significance. The ADP/O ratio was significantly decreased in the alcohol-fed groups when both the respiratory substrates were added. The data obtained demonstrated a beneficial effect of betulin on this parameter. Both betulin doses considerably increased the $\mathrm{ADP} / \mathrm{O}$ value in liver mitochondria with succinate-dependent respiration, whereas only the high dose of betulin $(100 \mathrm{mg} / \mathrm{kg})$ elevated this parameter up to the control value with statistical significance when pyruvate + malate were used as oxidizing substrates. The activities of the mitochondrial enzymes, such as NADH dehydrogenase (Complex I), succinate dehydrogenase (Complex II), and cytochrome c oxidase (Complex IV), were decreased in alcohol-treated rats (Fig. 2C-E). The treatment of rats from the ASH group with betulin dose-dependently activated NADH dehydrogenase and succinate dehydrogenase, whereas the activity of cytochrome $c$ oxidase remained unchanged.

Table II. Serum markers in rats with alcoholic steatohepatitis treated with betulin

\begin{tabular}{|l|c|c|c|c|}
\hline & Control & ASH & $\begin{array}{c}\text { ASH + betulin } \\
(\mathbf{5 0} \mathbf{~ m g} / \mathbf{k g})\end{array}$ & $\begin{array}{c}\text { ASH + betulin } \\
(\mathbf{1 0 0} \mathbf{~ m g} / \mathbf{k g})\end{array}$ \\
\hline Triglycerides (mol/L) & $2.06 \pm 0.269$ & $5.32 \pm 0.454^{\mathrm{a}}$ & $4.61 \pm 0.350^{\mathrm{ab}}$ & $4.20 \pm 0.282^{\mathrm{ab}}$ \\
\hline $\begin{array}{l}\text { Alkaline phospatase } \\
\text { (IU/L) }\end{array}$ & $150 \pm 22$ & $378 \pm 93^{\mathrm{a}}$ & $303 \pm 89^{\mathrm{a}}$ & $288 \pm 74^{\mathrm{a}}$ \\
\hline AST (IU/L) & $67.3 \pm 11.30$ & $124.6 \pm 28.93^{\mathrm{a}}$ & $102.0 \pm 23.81^{\mathrm{a}}$ & $95.3 \pm 13.36^{\mathrm{ab}}$ \\
\hline ALT (IU/L) & $48.2 \pm 10.51$ & $114.8 \pm 29.12^{\mathrm{a}}$ & $91.8 \pm 25.38^{\mathrm{a}}$ & $80.0 \pm 32.46^{\mathrm{ab}}$ \\
\hline TNF $\alpha(\mathrm{pg} / \mathrm{ml})$ & $62.3 \pm 13.8$ & $196.9 \pm 65.0^{\mathrm{a}}$ & $164.3 \pm 76.0^{\mathrm{a}}$ & $136.6 \pm 44.8^{\mathrm{ab}}$ \\
\hline Il-1 $\beta(\mathrm{pg} / \mathrm{ml})$ & $17.2 \pm 3.14$ & $27.4 \pm 6.24^{\mathrm{a}}$ & $22.8 \pm 6.10^{\mathrm{a}}$ & $20.3 \pm 5.88^{\mathrm{b}}$ \\
\hline TGF $\beta(\mathrm{pg} / \mathrm{ml})$ & $321 \pm 51$ & $664 \pm 99^{\mathrm{a}}$ & $438 \pm 80$ & $369 \pm 59^{\mathrm{b}}$ \\
\hline Hyaluronic acid (ng/ml) & $37.5 \pm 2.27$ & $60.6 \pm 9.30^{\mathrm{a}}$ & $51.8 \pm 14.00^{\mathrm{a}}$ & $35.3 \pm 10.80^{\mathrm{ab}}$ \\
\hline
\end{tabular}

The data are presented as means \pm SD. ALT: alanine; AST: aspartate aminotransferase; TNF $\alpha$ : tumor necrosis factor alpha; IL-1 $\beta$ : interleukin-1 $\beta$; TGF $\beta$ : transforming growth factor beta; ASH: alcoholic steatohepatitis. Significant difference $(p<0.05)$ : ${ }^{\mathrm{a}}$ vs. that of the Control group; ${ }^{\mathrm{b}} \mathrm{vs}$. that of the ASH group 
A
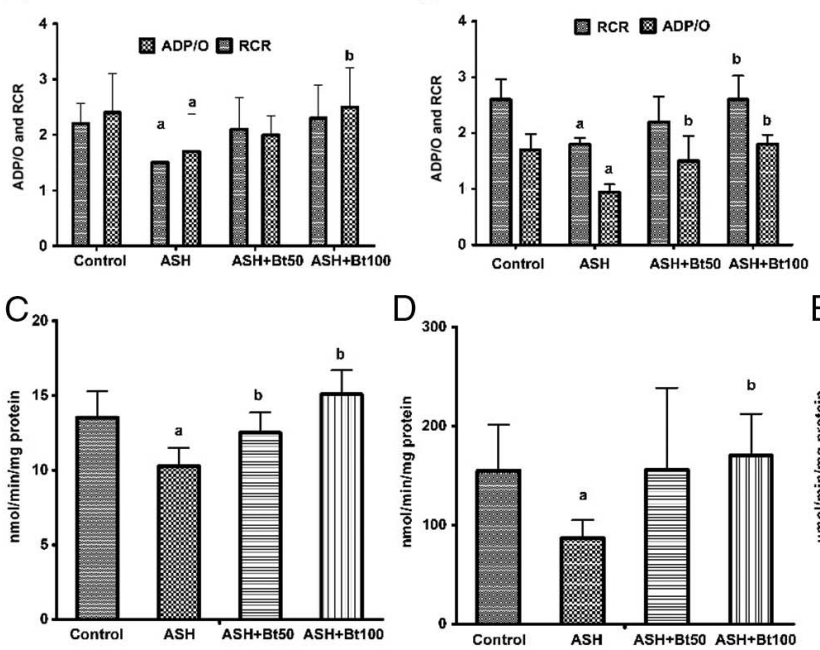

$\mathrm{F}$

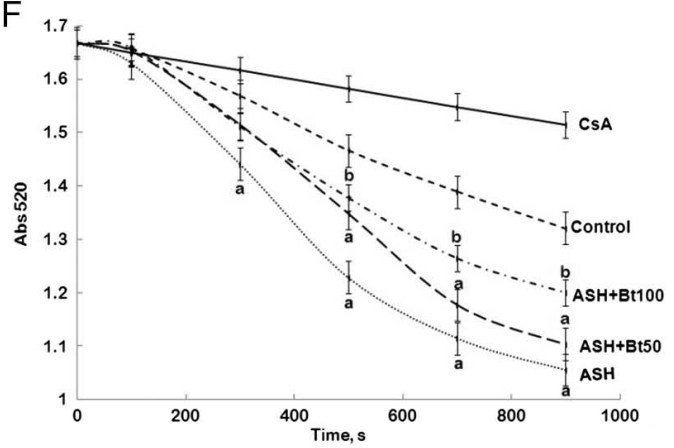

Fig. 2. Liver mitochondrial respiration parameters, electron transport chain enzyme activities and $\mathrm{Ca}^{2+}$-induced MPT rate. (A) The respiratory control ratio (RCR) calculated as the ratio of respiratory rates $\left(V_{3} / V_{4}\right)$ of mitochondria in state 3 and state 4 and the coefficient of phosphorylation (ADP/O ratio) with substrates for Complex I (pyruvate + malate); (B) RCR and ADP/O ratios with substrates for Complex II (succinate + rotenone); Mitochondrial respiration rates were determined as $\mathrm{nmol} \mathrm{O}_{2} / \mathrm{min} / \mathrm{mg}$ protein. (C) Complex I activity (nmol NADH oxidized/min/mg protein); (D) Complex II activity (nmol succinate oxidized/min $/ \mathrm{mg}$ protein); (E) Complex IV activity (nmol cytochrome $c$ oxidized/min/mg protein). (F) Representative $\mathrm{Ca}^{2+}$-induced swelling curves of rat liver mitochondria (MPT). The energized mitochondria swelling was registered as changes in the absorption of mitochondrial suspension at $520 \mathrm{~nm}$. All the data are presented as means $\pm \mathrm{SD}$. Mitochondria $(0.5 \mathrm{mg} \mathrm{protein} / \mathrm{ml})$ were incubated in the following media: $0.25 \mathrm{M}$ sucrose, $0.02 \mathrm{MTris}-\mathrm{HCl}$ and $0.001 \mathrm{M} \mathrm{KH}_{2} \mathrm{PO}_{4}, \mathrm{pH} 7.2,5 \mathrm{mM}$ succinate and the $\mathrm{Ca}^{2+}$ ions $(40 \mu \mathrm{M})$ were added at $25^{\circ} \mathrm{C}$. All the data are presented as means \pm SEM. Significant difference $(p<0.05):{ }^{a} \mathrm{vs}$. that of the Control group; ${ }^{b}$ vs. that of the ASH group

Figure $2 \mathrm{~F}$ shows representative curves of rat's liver MPT induced by calcium ions $(40 \mu \mathrm{M})$ in vitro. The calcium-induced MPT was prevented by CsA pretreatment. Chronic ethanol administration disturbed mitochondrial membrane stability and increased sensitivity to the accumulation of $\mathrm{Ca}^{2+}$ ions. The results obtained demonstrate that the treatment of ethanol-fed rats with both betulin doses (50 and $100 \mathrm{mg} / \mathrm{kg}$ ) obviously inhibited $\mathrm{Ca}^{2+}$-induced liver mitochondrial swelling in vitro. The rate of liver mitochondrial swelling in ASH animals treated with the higher betulin dose was close to that observed in control rats. 


\section{Effects of betulin on oxidative stress}

The oxidative stress-related parameters measured were significantly increased in the ethanol-treated group. The lucigenin-enhanced chemiluminescence of mitochondria was appreciably higher in this group as compared to the controls, suggesting an increase in superoxide anion generation (nearly 3.4-fold; Fig. 3A). The TBARS content in liver tissue was elevated (Fig. 3B), whereas the reduced GSH level was lowered (Fig. 3C) with statistical significance in comparison with the control group.

As was suggested, the changes in the intensity of chemiluminescence with lucigenin indicated that the betulin-treatment dramatically inhibited mitochondrial superoxide anion production. This parameter decreased dose-dependently on exposure to betulin at doses of 50 and $100 \mathrm{mg} / \mathrm{kg}$ (more than two- and threefolds, respectively). Similarly, both betulin doses significantly decreased the TBARS content to the same extent (about 1.6-fold), whereas the GSH level was partially raised in the liver of the ASH rats after treatment with the higher betulin dose $(100 \mathrm{mg} / \mathrm{kg})$.

\section{Discussion}

We evaluated the hepatoprotective efficacy of two doses of betulin in experimental ASH induced by ethanol administration. The histological picture of the liver of the ethanol-treated group, which was characterized by macro- and microvesicular steatosis and inflammatory signs, coincided with the biochemical data showing increased activities of the serum marker enzymes. The development of steatosis in the liver of ethanol-administered rats was confirmed by the elevated ratio of liver/body weight, the square of sudanophylic staining, and the serum and liver triglyceride contents. The rise in levels of the key proinflammatory cytokines, TNF $\alpha$, and IL-1 $\beta$ in the serum was consistent with the increase in inflammatory foci in the liver, which indicates development of the signs of hepatitis. The increased fibrogenic markers, serum TGF $\beta$ and hyaluronic acid values, indicated a tendency of increasing fibrogenesis in the liver of ethanol-treated rats, which is characteristic of ASH. Thus, the development of ASH in the ethanol-treated group was evident from the above histological and biochemical evaluation.
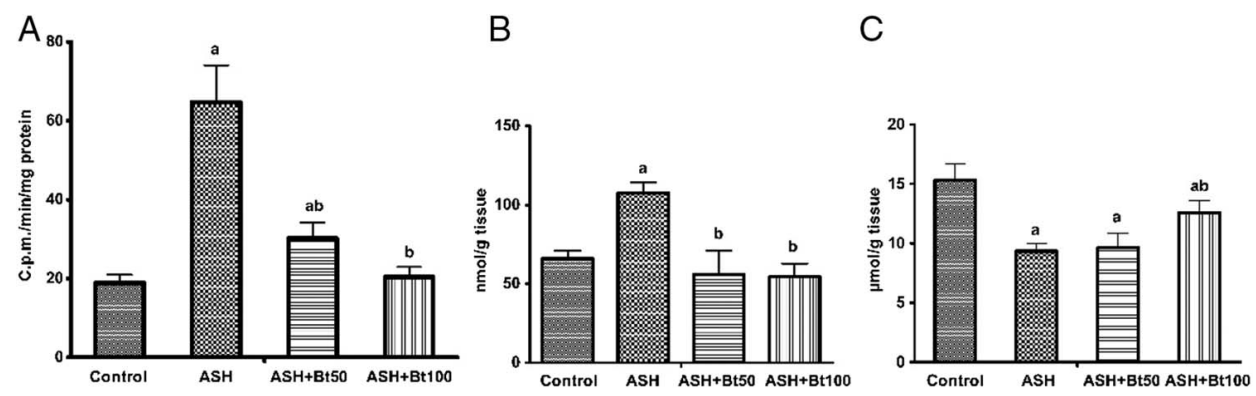

Fig. 3. Effect of betulin on ROS generation in liver mitochondria, TBARS and GSH content in liver tissue of rats with ASH. (A) The lucigenin-enhanced chemiluminiscence of mitochondria; (B) Thiobarbituric acid reactive substances in liver tissue; (C) Reduced glutathione content in liver tissue. The figures demonstrate significant radical scavenging and antioxidant efficacy of betulin. All the data are presented as means \pm SD. Significant difference $(p<0.05)$ : ${ }^{\mathrm{a}} \mathrm{vs}$. that of the Control group; ${ }^{\mathrm{b}} \mathrm{vs}$. that of the ASH group 
Our present findings first suggest that betulin at the dose of $100 \mathrm{mg} / \mathrm{kg} \mathrm{b.w}$. can prevent progression of steatosis as well as inflammatory and fibrogenic responses in the liver of rats chronically administered with ethanol. The treatment of alcohol-administered rats by this dose of betulin substantially ameliorated the histological signs of steatosis in the liver, which significantly decreased the liver/body weight ratio and triglyceride contents in the serum and the liver, whereas the sudanophylic area in liver slides was lowered, but without statistical significance. The higher dose of betulin $(100 \mathrm{mg} / \mathrm{kg})$ showed clear anti-inflammatory properties, decreasing the number of inflammatory foci in the liver and the serum content of proinflammatory cytokines. The lowered content of serum fibrogenic markers, the main profibrogenic cytokine TGF $\beta$, and hyaluronic acid can indicate the antifibrotic activity of betulin. However, similar effects of betulin at a dose of $50 \mathrm{mg} / \mathrm{kg} \mathrm{b} . \mathrm{w}$. were significantly less expressed as compared to the higher dose of betulin.

Progression of ASH is stipulated by many factors, most important among them being oxidative stress (3) and enhanced formation of lipid peroxidation end-products, which cause hepatocyte toxicity (9).

Mitochondrial dysfunction is associated with oxidative damage, calcium dyshomeostasis, defective ATP synthesis, or induction of the MPT pore $(25,30)$ and is considered as one of the earliest manifestations of alcoholic liver injury (38). Increased ROS production and its consequences, such as GSH depletion, modification of proteins with end-products of lipid peroxidation, damage of mitochondrial membranes, etc., is major events associated with mitochondrial dysfunction in alcoholic liver diseases (5). We demonstrated that, in the liver of rats, long-term administration of ethanol caused mitochondrial abnormalities characterized by a dramatic increase in mitochondrial superoxide anion production (around 3.5-fold); lowering of complex I, II, and IV activities; disturbances in mitochondrial respiration; and uncoupling of oxidative phosphorylation, as is suggested by the decreased RCR and ADP/O parameters.

Targeting mitochondria with several antioxidative agents can be helpful for preventing dysfunction of the mitochondria and pharmacological corrections of liver disease (11). This provides a rationale for application of antioxidants in effective treatment of ASH and substantiates the use of betulin, a scavenger of free radicals (32) in this study.

In the present work, we showed that chronic alcohol intoxication in rats resulted in considerable impairments in mitochondrial functional activity: the activities of the electron transport chain complexes as well as mitochondrial coupling of oxidation and phosphorylation (RCR value) and the efficiency of phosphorylation (ADP/O value) decreased and mitochondrial ROS generation was enhanced. Similarly, in this study, the susceptibility of mitochondria to $\mathrm{Ca}^{2+}$-induced permeability transition pore formation considerably increased in ethanol-treated rats.

It is well-known that oxidative impairments in mitochondria and disturbed mitochondrial $\mathrm{Ca}^{2+}$ homeostasis can cause activation of the inner membrane MPT $(7,15)$. The MPT pore is a non-selective calcium-sensitive channel that allows non-selective release of different solutes $(<1,500 \mathrm{Da})$ including secondary messengers, sequestered $\mathrm{Ca}^{2+}$ and proapoptotic factors across the membrane $(2,7)$. The operation of $\mathrm{Ca}^{2+}$-mediated membrane pores causes collapse of the membrane potential, large amplitude mitochondrial swelling, membrane rupture, mitochondrial uncoupling as well as ATP depletion and induces ROS productions (6). The MPT plays a crucial role in apoptotic and necrotic cell death (2), whereas inhibition of MPT pore opening prevents these pathological changes in cells and mitochondria. The data in the literature suggest that long-term ethanol intoxication causes a decline in the mitochondrial 
membrane potential and enhances the sensitivity of mitochondria to calcium-induced MPTs, respiratory chain dysfunction, and hepatocyte apoptosis/necrosis $(5,9,27)$.

As demonstrated in this study, betulin administration during intoxication significantly decreased mitochondrial production of superoxide anions and TBARS concentration and increased GSH content in the liver of ethanol-treated rats, preventing disturbances in redoxbalance in liver cells. Betulin treatment normalized the parameters of mitochondrial respiration (RCR) and oxidative phosphorylation (ADP/O), restored the activities of complex I and II, but did not affect Complex IV activity. Simultaneously, betulin treatment of rats with $\mathrm{ASH}$ resulted in a dose-dependent increase in mitochondrial resistance to $\mathrm{Ca}^{2+}$-induced MPT pore opening. We suggest that the beneficial hepatoprotective effect of betulin in ASH can be connected with the antioxidative properties of this compound and can be realized via its mitochondrial effects attributed to inhibition of the MPT.

\section{Acknowledgements}

The study was financially supported by the State Program of Belarus "Fundamental and Applied Sciences for Medicine," Subprogram 11.1 "Fundamental and Applied Medicine” (no. 1.17).

\section{Conflict of interest}

The authors declare no conflict of interest.

\section{REFERENCES}

1. Akerboom TP, Sies H: Assay of glutathione, glutathione disulfide, and glutathione mixed disulfides in biological samples. Methods Enzymol. 77, 373-382 (1981)

2. Alavian KN, Beutner G, Lazrove E, Sacchetti S, Park HA, Licznerski P, Li H, Nabili P, Hockensmith K, Graham M, Porter GA Jr, Jonas EA: An uncoupling channel within the c-subunit ring of the $\mathrm{F}_{1} \mathrm{~F}_{\mathrm{O}}$ ATP synthase is the mitochondrial permeability transition pore. Proc. Natl. Acad. Sci. U. S. A. 111, 10580-10585 (2014)

3. Albano E: Alcohol, oxidative stress and free radical damage. Proc. Nutr. Soc. 65, 278-290 (2006)

4. Bai T, Yang Y, Yao YL, Sun P, Lian LH, Wu YL, Nan JX: Betulin alleviated ethanol-induced alcoholic liver injury via SIRT1/AMPK signaling pathway. Pharmacol. Res. 105, 1-12 (2016)

5. Bailey SM, Cunnunham CC: Contribution of mitochondria to oxidative stress associated with alcohol liver disease. Free Radic. Biol. Med. 32, 11-16 (2002)

6. Batandier C, Leverve X, Fontaine E: Opening of the mitochondrial permeability transition pore induces reactive oxygen species production at the level of the respiratory chain complex I. J. Biol. Chem. 279, 17197-17204 (2004)

7. Bernardi P, Lisa DF: The mitochondrial permeability transition pore: molecular nature and role as a target in cardioprotection. J. Mol. Cell Cardiol. 78, 100-106 (2015)

8. Buege JA, Aust SD: Microsomal lipid peroxidation. Methods Enzymol. 52, 302-310 (1978)

9. Cederbaum AI, Lu Y, Wu D: Role of oxidative stress in alcohol-induced liver injury. Arch. Toxicol. 83, 519-548 (2009)

10. Ci X, Zhou J, Lv H, Yu Q, Peng L, Hua S: Betulin exhibits anti-inflammatory activity in LPS-stimulated macrophages and endotoxin-shocked mice through an AMPK/AKT/Nrf2-dependent mechanism. Cell Death Dis. 8, 2798 (2017)

11. Diogo CV, Grattagliano I, Oliveira PJ, Bonfrate L, Portincasa P: Re-wiring the circuit: mitochondria as a pharmacological target in liver disease. Curr. Med. Chem. 18, 5448-5465 (2011)

12. Golovach NG, Cheshchevik VT, Lapshina EA, Ilyich TV, Zavodnik IB: Calcium-induced mitochondrial permeability transitions: parameters of $\mathrm{Ca}^{2+}$ ion interactions with mitochondria and effects of oxidative agents. J. Membr. Biol. 250, 225-236 (2017)

13. Johnson D, Lardy HA: Isolation of liver or kidney mitochondria. Methods Enzymol. 10, 94-96 (1967) 
14. Kim M-S, Ong M, Qu X: Optimal management for alcoholic liver disease: conventional medication, natural therapy or combination? World J. Gastroenterol. 22, 8-23 (2016)

15. Kowaltowski AJ, Castilho RF, Vercesi AE: Mitochondrial permeability transition and oxidative stress. FEBS Lett. 495, 12-15 (2001)

16. Li Y, He K, Huang Y, Zheng D, Gao C, Cui L, Jin YH: Betulin induces mitochondrial cytochrome c release associated apoptosis in human cancer cells. Mol. Carcinog. 49, 630-640 (2010)

17. Lin W-Y, Lin F-H, Sadhasivam S, Savitha S: Antioxidant effect of betulin on porcine chondrocyte behavior in gelatin/C6S/C4S/HA modified tricopolimer scaffold. Mater. Sci. Eng. 30, 597-604 (2010)

18. Liu J, Liu Y, Mao Q, Klaassen CD: The effects of 10 triterpenoid compounds on experimental liver injury in mice. Fundam. Appl. Toxicol. 22, 34-40 (1994)

19. Louvet A, Mathurin P: Alcoholic liver disease: mechanisms of injury and targeted treatment. Nat. Rev. Gastroenterol. Hepatol. 12, 231-242 (2015)

20. Lowry OH, Rosebrough NJ, Farr AL, Randall RJ: Protein measurement with the Folin phenol reagent. J. Biol. Chem. 193, 265-275 (1951)

21. Lukivskaya O, Naruta E, Sadovnichy V, Kirko S, Buko VU: Reversal of experimental ethanol-induced liver steatosis by borage oil. Phytother. Res. 26, 1626-1631 (2012)

22. Lukivskaya O, Patsenker E, Buko VU: Protective effect of ursodeoxycholic acid on liver mitochondrial function in rats with alloxan-induced diabetes: link with oxidative stress. Life Sci. 80, 2397-2402 (2007)

23. Mathews S, Xu M, Wang H, Bertola A, Gao B: Animals models of gastrointestinal and liver diseases. Animal models of alcohol-induced liver disease: pathophysiology, translational relevance, and challenges. Am. J. Physiol. Gastrointest. Liver Physiol. 306, 819-823 (2014)

24. Müller-Peddinhaus R, Wurl M: The amplified chemiluminescence test to characterize antirheumatic drugs as oxygen radical scavenger. Biochem. Pharmacol. 36, 1125-1132 (1987)

25. Nassir F, Ibdah JA: Role of mitochondria in alcoholic liver disease. World J. Gastroenterol. 20, 2136-2142 (2014)

26. Oh SH, Choi JE, Lim SC: Protection of betulin against cadmium-induced apoptosis in hepatoma cells. Toxicology 22, 1-12 (2006)

27. Pastorino JG, Marcineviciute A, Cahill A, Hoek JB: Potentiation by chronic ethanol treatment of the mitochondrial permeability transition. Biochem. Biophys. Res. Commun. 265, 405-409 (1999)

28. Singal AK, Jampana SC, Weinman SA: Antioxidants as therapeutic agents for liver disease. Liver Int. 31, 1432-1448 (2011)

29. Singer TP: Determination of the activity of succinate, NADH, choline, and alpha-glycerophosphate dehydrogenases. Methods Biochem. Anal. 22, 123-175 (1974)

30. Smith RA, Hartley RC, Cochemé HM, Murphy MP: Mitochondrial pharmacology. Trends Pharmacol. Sci. 33, 341-352 (2012)

31. Soica CM, Dehelean CA, Peev C, Aluas M, Zupkó I, Kása P Jr, Alexa E: Physico-chemical comparison of betulinic acid, betulin and birch bark extract and in vitro investigation of their cytotoxic effects towards skin epidermoid carcinoma (A431), breast carcinoma (MCF7) and cervix adenocarcinoma (HeLa) cell lines. Nat. Prod. Res. 26, 968-974 (2012)

32. Szuster-Ciesielska A, Plewka K, Kandefer-Szerszeń M: Betulin, betulinic acid and butein are inhibitors of acetaldehyde-induced activation of liver stellate cells. Pharmacol. Rep. 63, 1109-1123 (2011)

33. Tang BL: Sirt1 and the mitochondria. Mol. Cells 39, 87-95 (2016)

34. Vidya L, Malini MM, Varalakshmi P: Effect of pentacyclic triterpens on oxalate-induced changes in rat erythrocytes. Phamacol. Res. 42, 313-316 (2000)

35. Volynets V, Louis S, Pretz D, Lang L, Ostaff MJ, Wehkamp J, Bischoff SC: Intestinal barrier function and the gut microbiome are differentially affected in mice fed a western-style diet or drinking water supplemented with fructose. J. Nutr. 147(5), 770-780 (2017)

36. Wan Y, Jiang S, Lian LH, Bai T, Cui PH, Sun XT, Jin XJ, Wu YL, Nan JX: Betulinic acid and betulin ameliorate acute ethanol-induced fatty liver via TLR4 and STAT3 in vivo and in vitro. Int. Immunopharmacol. 17, 184-190 (2013)

37. Wikström M, Casey R: The oxidation of exogenous cytochrome c by mitochondria. Resolution of a long-standing controversy. FEBS Lett. 183, 293-298 (1985)

38. Yip WW, Burt AD: Alcoholic liver diseases. Semin. Diagn. Pathol. 23, 149-160 (2006) 